\title{
Culturas invisibles de la pobreza urbana en Lima: hacia una teoría descolonial desde el capitalismo financiero global
}

\section{Invisible cultures of urban poverty in Lima: Towards a decolonial theory from global financial capitalism}

\section{ABSTRACT}

The article presents some aspects of reflection from the decolonial theory as situations of typical cases about new invisible cultures of urban poverty in Metropolitan Lima from the framework of the impact of financial capitalism and its new forms of coloniality.

KeYwords: Lima; capitalism; cultures; decolonial; poverty. 


\section{Ubicación teórica metodológica}

E capitalismo financiero cognitivo global procesa una nueva dinámica de la pobreza y riqueza en inéditas formas y contenidos. Su investigación supone una mirada múltiple y multidimensional, pues en sus diversos aspectos esconde sus propias causas y manifestaciones estructurales en términos de ingreso, género, raza, derechos y oportunidades. El fenómeno se hace visible en periodos de crecimiento con sus exclusiones e inclusiones (Cattani y Mota, 2013) o en coyunturas de crisis estructurales (Pimentel, 2013) en procesos inéditos de individuación, sociabilidad, socialización y construcción de identidades. La automatización producto de la nueva revolución industrial crea un desempleo estructural afectando en nuestras singularidades la pobreza en todos sus espacios. Corresponde por tanto sociológicamente conocer en sus diferencias y unidad las nuevas modalidades específicas de reproducción de la pobreza en el capitalismo cognitivo global.

La presencia de los nuevos pobres en América Latina, su impacto social y político salta a la vista. La construcción de una teoría descolonial de la nueva dinámica de la pobreza global tiene que tomar como base la colonialidad del poder y racialización (Quijano, 2000, 2014), los procesos de depredación por desposesión (Harvey, 2005), la explotación y «epistemicidio» cultural (De Sousa Santos), la violencia de la nueva acumulación originaria global (Bilakowsky y Costa, 2017), la heterotopía (Martins, 2012) y transculturización de las sociedades (Ríos, 2011) entre otros aportes.

Podemos elegir diferentes problematizaciones para su análisis como lo hacen por ejemplo como poblaciones extinguibles (Bilakowsky y Costa, 2017), el imaginario, discurso y campo simbólico socio político (Barba, 2009), la falacia del «desarrollo» (Buitrago, 2010), la situación indígena y migratoria (Contreras y otros, 2012), el infoproletariado (Antunes, 2014), el género (Eguía y Pioviani, 2015) y las experiencias nacionales de políticas (Cimadamore, 20018).

El imaginario de la pobreza como «magma» penetra en la vida cotidiana de los nuevos pobres descubriendo estructuraciones profundas o mentalidad de los actores. Base sobre la cual se elaboran los discursos como esquemas que estructuran la vida cotidiana como actores. Un orden simbólico que individualiza, sociabiliza, socializa y marcan las identidades de los actores en sus prácticas cotidianas. Aquí las acciones y estructuraciones van más allá de las determinaciones estructurales. Los actores decodifican y revolucionan en sus prácticas los discursos sistémicos de control de poder produciendo discursos contra culturales como expresión vital de las nuevas sociabilidades de vida. Lo pobres construyen o reproducen sus discursos en espacio simbólicos concretos de la vida social. La sociología de la pobreza puede abordarse en sus dinámicas estructurales y no estructurales, de estructura y cambio social en sus aspectos económico social, política, cultural, religioso, psicológico, demográfico, jurídico, cotidiano. No existe un enfoque y modelo único. Veamos algunos otros enfoques que enriquezcan nuestra mirada desde los actores.

Para el 2015 la CEPAL consideraba que las brechas estructurales en los mercados laborales y amplias diferencias en el acceso a las oportunidades, derechos y prestaciones entre distintos grupos de la población representan un obstáculo clave para la superación de la pobreza y la reducción de su vulnerabilidad (CEPAL, 2015). Como hemos señalado para su conocimiento podemos recurrir a diferentes miradas o esquemas específicos como el de Pierre Bourdieu. Esquema que nos permitiría captar la pobreza como un conjunto de esferas de juego relativamente autónomo, de carácter socio económico, político, religioso, intelectual, estético, etc. Campos de pobreza que se caracterizan por contar con valores particulares, principios regulatorios, espacios de lucha que compiten por la apropiación de una forma determinada de capital (económico, cultural, simbólico). En ese sentido, los campos de pobreza serían todo un sistema estructurado de fuerzas objetivas, con una gravedad específica que se impone a objetos y agentes (Bourdieu y Wacquant, 1995)

Para Anthony Giddens la problemática tenemos que ubicarlo en relación con los imaginarios, los discursos y los paradigmas en interacción constante, ya que elementos de los paradigmas también pueden llegar a formar parte de los imaginarios a través del proceso de una «doble hermenéutica» (Giddens, 1993). Rastrear la incidencia de conceptos aportados por agentes "profanos", mientras que las nociones acuñadas por los metalenguajes de las ciencias sociales reingresan y afectan rutinariamente al campo de las prácticas sociales. Esto significa que existe una especie de espiral dentro/fuera entre ciencia y sociedad. 
El Consenso de Washington con sus instancias representativas (BM, FMI, OCDE, etc.) y gobiernos neoliberales centran su investigación en el marco de la teoría de las políticas sociales «minimalistas» e instrumentos de inversión en el capital humano (De Ferranti et al., 2000). Consideran el crecimiento económico como el mecanismo fundamental para reducir la pobreza e incorporación individual al mercado para lo cual se hace fundamental implementar crecientes procesos de privatización de activos públicos y reformas comerciales, fiscales y financieras, sistemas de seguro social y mercados laborales privatizados. Como también impulsar la descentralización de servicios sociales, focalizar programas dirigidos a los más pobres y crear fondos de inversión social.

Mario Sandoval en este contexto destaca que existen dos enfoques que resaltan en su investigación (Sandoval, 2014). El enfoque cuantitativo que centra su interés en el ingreso, ahorro, consumo, cantidad de bienes, etc. Enfoque que Philippe Cornil le denomina la concepción objetivista de la pobreza. En esta línea de análisis se ubican junto con los economistas, los planificadores sociales y las autoridades de Gobierno y los sociólogos cuantitativos. Lo central de esta perspectiva es llegar a obtener índices que permitan definir un umbral de pobreza y de esa manera decir quiénes son pobres y quiénes no lo son. Para esto, se construyen definiciones operacionales, técnicas y estadísticas, sin llegar a constituir teorías de la pobreza. Aquí pobres son los que tienen ingresos totales superiores a los necesarios para adquirir la canasta básica de alimentos y menores al doble de ese valor. Los que no logran reunir los ingresos suficientes para adquirir esta canasta son llamados «indigentes», es decir, los más pobres que los pobres. Por tanto, pobre es el que no satisface las necesidades básicas tales como comer, beber, vestirse, etc.

El enfoque cualitativo socio antropológico y psicológico presta atención a otros aspectos de la problemática de la pobreza. Se interesa más por la parte subjetiva e intersubjetiva de la problemática. Vemos surgir una corriente que comprende la pobreza como una subcultura. Mirada heredada de planteamientos como del antropólogo Oscar Lewis que ubicaba la pobreza como una dimensión y una subcultura específica que se produce y reproduce socialmente en el tiempo. No es solo una cuestión de miseria económica, desorganización o ausencia de alguna cosa, también es un elemento positivo sin el cual los pobres no podrían vivir. «La cultura de la pobreza es a la vez una adaptación y una reacción de los pobres a su posición marginal en una sociedad estratificada altamente individualizada y capitalista» (Lewis, 1969).

La subcultura de la pobreza aparece con relación al conjunto de la sociedad resaltando la ausencia de participación efectiva y de integración de los pobres. La ausencia de recursos económicos, la segregación social, la discriminación, el miedo, la desconfianza, la apatía y el desarrollo de soluciones locales a los problemas que los aquejan. La pobreza comunitaria ubicaba las condiciones de vivienda, hacinamiento, promiscuidad, organización más allá del núcleo familiar y su cultura marginal. A nivel familiar resalta una infancia corta y desprotegida, una iniciación precoz de la sexualidad, realización de uniones libres o matrimonios consensuales, abandono de mujeres y niños, tendencia al matriarcado, predisposición al autoritarismo masculino. A nivel individual un sentimiento de estar al margen, impotencia, dependencia, inferioridad, resignación, fatalismo, bajo nivel de aspiraciones. En sus aspectos positivos muestran el hecho de vivir el presente afirmando el "don» de la espontaneidad y de la aventura, el gusto, el placer de los sentidos y la satisfacción de los instintos, es decir, los mecanismos de adaptación de la cultura a los desafíos del capitalismo de consumo global.

Para Ruwen Ogien la cultura de la pobreza se expresa por ejemplo a nivel familiar, la desorganización de la familia, las uniones libres, la existencia de familias monoparentales con tendencia al matriarcado; la ausencia de integración, la marginalidad en relación a la institucionalidad existente, la desorganización local. A nivel individual, la irracionalidad de sus conductas, la preferencia por el presente, la imposibilidad de elaborar proyectos para el futuro, la pasividad, la dependencia, la actitud de resignación y fatalismo y el autoritarismo, asociado al sentimiento de superioridad masculina. Un modo de vida particularmente estable y persistente, transmitido de una generación a otra por las líneas familiares» (Ogien, 1983).

Para otros autores como Richard Huggart estudiar la pobreza supone principalmente prestar atención etnosocial a la vida cotidiana desde aspectos como la organización del espacio y habitats, itinerarios de desplazamientos estacionales o semanales, ritmos y lugares de trabajo y/o de recreación, relación entre los sexosyentrelas generaciones, estructura de la constelación familiar, educación de los hijos, articulación de prácticas 
económicas culturales y religiosas, repertorio de objetos materiales y de bienes, etc. Una aproximación teórico/ vivencial dándole gran importancia al uso del lenguaje, el léxico corriente, las modalidades de expresión, los dialectos urbanos, los acentos y las entonaciones utilizadas por las clases populares entre la tradición y la modernidad cultural (Hoggart, 1970).

Entre sus conclusiones plantea «que los miembros de las clases populares son mucho menos influenciables por su consumo cultural de lo que parecen serlo o de lo que dicen serlo». Destaca que pasada la adolescencia, los jóvenes vuelven fácilmente a adoptar actitudes de su clase, es decir que los jóvenes «retoman rápidamente el ritmo y modo de vida de sus mayores». Señala el interés por las actividades manuales. Notándose muchas veces que en las clases populares hay una resistencia al cambio. Lo más impresionante dice no es la tendencia a conservar las tradiciones de los mayores sino a crear nuevas tradiciones que sean transmitidas a las generaciones futuras. Visualiza un peligro y un riesgo: el aumento de los bienes disponibles para la diversión a diferencia de la pasada tradición de la clase obrera lectoras que poseían la reflexión y el saber para ser la vanguardia del movimiento obrero.

Cabe destacar así mismo la influencia de la vieja tradición funcionalista de la teoría de la modernización y el cambio social en los estudios de la pobreza rural urbana. Esta «teoría» explica el fenómeno de la pobreza como producto del cambio social, es decir, como resultado indeseable de los procesos de modernización y urbanización producto de la destrucción del mundo tradicional rural y la expulsión de los campesinos y pueblos rurales a las grandes ciudades. Actores que entre una cultura tradicional ligada a la tierra y una cultura moderna urbanizada que les exigía otro tipo de habilidades y aprendizajes, en esta tensión cultural se constituyeron «masas anómicas pobres y heterónomas» (Dubet, 1987, 1989).

La perspectiva constructivista nos brinda otra mirada para investigar la problemática de la pobreza. Parte del hecho de reconocer que «la» realidad no existe como fenómeno único, externo, estático e inmutable, el que debe ser conocido, re-conocido y aprehendido por el investigador, sino más bien, la realidad aparece como una construcción social, es decir, lo real-existente y conocible puede ser construido por los observadores y los observados, los que -en definitiva- son sus constructores. Aquí, el pobre como sujeto conocedor en tanto capaz de otorgar un valor al conocimiento que él crea. Por tanto, el concepto de pobre es un concepto relativo ya que se puede aplicar a diferentes situaciones, categorías u oficios, sin embargo a partir del momento en que la persona asume la categoría de "asistido», es decir, cuando recibe una ayuda a raíz de su situación de carencia, podemos hablar de pobreza.

Cabe aquí destacar planteamientos como de Vercauteren que entienden la pobreza como exclusión de clase (Vercauteren, 1970). Asocian la condición de pobreza a la irregularidad de un ingreso y la conceptualiza como «sub-proletarios». La civilización industrial y urbana determina una forma particular de pauperismo o «subproletarios» caracterizados por la no propiedad de los medios de producción, la inexistencia de una prestación laboral estable y la ausencia de un ingreso permanente, baja escolarización y una ausencia de movilidad social ascendente. Actores donde existe una "temporalidad explosiva», la que se traduce en violencia cotidiana; esta no es una violencia organizada contra un sistema de dominación, es la "cólera social» o lo que Dubet denomina la «violencia sin sentido». Como su inmediatez, organización incoherente del tiempo, incertitud permanente, oposición entre la vida privada y la vida pública. Los pobres tienden a replegarse en la vida privada, al interior de la familia, aunque ésta, a raíz de los conflictos conyugales y parentales, sea un verdadero infierno. La "ceguera cultural» contribuye a que los pobres disfracen su realidad y construyan otra realidad imaginaria, es decir, el consumo de ideología dominante no les permite ver una realidad social determinada (su realidad de pobreza), y se crean status ficticios, pasando a ver la pobreza como un estado natural, con lo cual devienen conformistas.

Los pobres ven su destino ciego, dominado por fuerzas sobrenaturales (Parker, 1992), acosados por la fatiga, el sueńo y la muerte. En su vida la presencia del fracaso y la angustia es permanente; mantienen una incapacidad de ser y decir «nosotros», es decir, de cohesionarse en torno a intereses comunes y actuar organizadamente en la defensa de sus derechos, en la lucha política por el poder o por la conquista de un nivel de vida mejor. Los subproletarios no poseen ninguna organización política y ninguna forma de conciencia. En este aspecto un punto central en el análisis de Vercauteren acerca de los pobres es el relacionado con su ideología. Al respecto plantea que los subproletarios (los pobres) tienen una "conciencia social melancólica», esta conciencia social sería melancólica puesto que su representación del mundo se constituye 
a partir de un núcleo segurizante. Este núcleo consiste en el consumo de un estilo de vida que expresa la riqueza. Este estilo de vida se promociona por todas partes en los actuales contextos urbanos, a través de los afiches publicitarios y particularmente a través de la televisión, y es introyectado por los subproletarios. Su precariedad económica permanente les imposibilita realizar ese estilo de vida que se les muestra y que han interiorizado, por lo tanto, surge la angustia, la desesperación, la frustración y la resignación.

En una perspectiva crítica como bien destaca Sandoval por la forma de definir y comprender a los subproletarios está en las antípodas de la concepción del mismo sujeto (Fanon, 1969). Para Fanon, los subproletarios son la fuerza revolucionaria que luchará por los cambios, para Vercauteren son todo lo contrario. En una posición intermedia se encuentra Lewis cuando seńala que los subproletarios tienen poco espíritu revolucionario, y que en algunos casos desarrollan tendencias conservadoras. En esta misma línea Jean Labbens (1978) pero en otra orientación plantea que «la pobreza, tal como la entendemos, corresponde a lo que nuestros ancestros llamaban pauperismo o indigencia. Esta noción evoca inmediatamente aquella de la subsistencia: el indigente es aquel que no tiene todos los medios necesarios para sobrevivir o hacer sobrevivir a aquellos que dependen de él». Utilizando los conceptos weberianos de status, poder y clase señala que el pobre se sitúa al nivel más bajo de estas tres dimensiones: al pobre le falta fortuna y una ocupación remunerada (clase), le falta fuerza social (poder) y carece de respetabilidad (status).

En este debate Labbens rechaza la posibilidad que la pobreza se constituya una cultura específica, más bien señala que existe un conjunto de prácticas ligadas a la posición social de los pobres, determinadas por su exclusión y agrupa las características de la pobreza en cuatro categorías, a saber: La primera hace referencia a la débil relación de los pobres con la institucionalidad de la sociedad en su conjunto. Esta falta de integración social se debería a la cesantía prolongada, al subempleo y a los bajos salarios. La segunda, los pobres tienen una cultura de provincia, aunque vivan en el corazón de la capital, desarrollando lazos de solidaridad similares a pueblos campesinos. Junto a esto se destaca la debilidad de las organizaciones de los pobres. La tercera, desde el punto de vista familiar, la cultura de la pobreza se caracteriza por la gran cantidad de uniones libres y pasajeras (convivencias), siendo la madre el personaje central de la familia. En el seno familiar la violencia es recurrente, ya sea entre la pareja o hacia los hijos. Otro rasgo es la iniciación precoz en el trabajo y en la vida sexual. Y, la cuarta característica a nivel individual, la pobreza engendra un sentimiento de marginalidad, de impotencia, de dependencia y de inferioridad. Esto se expresa en una resignación frente al futuro y en un fatalismo en relación al presente.

Finalmente, destaca la corriente que comprende la pobreza como un comportamiento fragmentado. Bajo la influencia de F. Dubet en la década de los 80 un equipo de investigadores chilenos realizó un estudio sobre los pobladores, partiendo de la constatación que las lógicas de acción de ellos no responden a un principio único articulador. La clave para su estudio es partir desde el actor mismo, (de sus acciones) más que desde teorías generales de la sociedad. Destacan el hecho de comprender las conductas de los pobladores, sus identificaciones, sus proyectos y a partir de ahí interpretar y teorizar. Los pobladores pobres tienen una extrema diversidad y jamás se articulan en torno a un principio central. La pluralidad de conductas (comportamiento fragmentado) impone la necesidad de contar con un marco teórico que dé cuenta de esta diversidad, sin privilegiar un elemento sobre otro. Marco teórico conocido como "Sistemas de Acción de los Pobladores».

Actores que se perciben a sí mismos de diferentes formas, por una parte, se sienten excluidos del consumo, de la participación social, de las redes de influencias, pero tampoco están completamente excluidos, no forman un ghetto. Ellos mismos se perciben como trabajadores explotados o sin trabajo, es decir, existen una identificación con la clase obrera. La exclusión y explotación son dos dimensiones que revelan la manera de autodefinición. Los otros dos principios son la participación y la ruptura. Entonces, explotación/ exclusión y participación/ruptura conforman la matriz de análisis propuesta por F. Dubet.

\section{Trayectorias culturales de individuación, socialización e identidades de los nuevos pobres en Lima}

\section{Caso 1. Ser mujer indigena en la urbe}

Lima es una ciudad que alberga aproximadamente a un tercio de la población del Perú, donde la mayoría 
de sus habitantes proceden de las diferentes provincias del país, y cuyas prácticas culturales son muy diversas. Tal es el caso de la comunidad Shipibo-Conibo de Cantagallo en el Rímac. Grupo étnico que desde una perspectiva de género nos presenta claramente como el ser indígena es una limitante para poder alcanzar mejores expectativas de vida.

Tal es el caso de la etnia shipibo-conibo del Asentamiento Humano de Cantagallo en Lima. El Asentamiento se ubica en el distrito del Rímac, a la altura del kilómetro 6.5 de la avenida Evitamiento, frente al mercado de flores de Piedra Lisa. Al cruzar la avenida, uno se encuentra con una pequeña losa de fulbito entre un depósito de maquinarias de la municipalidad de Lima Metropolitana y la feria «las Malvinas». A simple vista uno reconoce el asentamiento por los puestos de comida típica de la selva y los colores de las casas con motivos amazónicos. Existen dos entradas principales para acceder al lugar. Uno por el que transitan obreros y maquinaria del proyecto «Río Verde» de la municipalidad. Y, otro, que lleva a la entrada del segundo nivel, donde vive gente tanto de la sierra como de la selva y en la cual se ubica la escuela bilingüe de Cantagallo.

Al caminar por el lugar uno puede ver el colorido de las casas (hechas de madera), todas con motivos amazónicos, y cuyos muros son intervenidos muchos de ellos por artistas grafiteros de la ciudad. Pero, fuera del colorido y lo llamativo que pueden resultar las casas las casas no cuentan con servicios de agua y desagüe, lo que deviene en problemas en la piel y gastrointestinales. Además, las casas son precarias para soportar el invierno limeño provocando, sobre todo en nińos y ancianos, problemas respiratorios. A pesar de ello, la gente, sobre todo niños, se muestran alegres y amables. Es común escuchar que en sus hogares pasan las tardes con música de su tierra.

Claudia Pacaya Cruz es una actora típica de de este grupo. Dice: Yo me llamo Claudia Pacaya Cruz, mi nombre en shipibo es "Sanquë Gisfe». Yo he venido de la comunidad santa Isabel, cuando tenía 18 años. Acá (en Lima) he terminado mi secundaria, en el colegio de mujeres "Sagrada Familia» de la Victoria. Estudié en el instituto Cimas, quería estudiar más pero ya no tenía posibilidad, me quedé en 2 do ciclo de secretaría, de ahí comencé a trabajar porque ya no podía pagar mi cuarto, mis pensiones, mis pasajes la comida, ya no podía ya. Me salí y me dediqué a trabajar, he trabajo en artesanía, así haciendo mi artesanía, así terminé mi secundaria. Ya no podía más tanto que ya no me cubría, me dediqué a trabajar, mi arte, artesanía, pintar, bordado. De ahí viajaba con mi mamá en provincia a llevar mis trabajos. Primero yo vivía por San Juan de Miraflores, alquilaba un cuarto, de ahí terminé mi secundaria mis, mis institutos, de ahí acá vine. Acá estamos como 13, 14 años que estamos yendo ya. En octubre es aniversario de la comunidad.

Ocupar el espacio público es una forma de vivir como familia extensa y nuclear y en relación con el otro: el andino: «Hemos venido acá como cinco personas. Era una feria de las tres regiones, y nos invitaron. Hemos venido para agarrar puestos para exponer nuestras artesanías. Todo abajo era pampa, el primer nivel, allí donde habíamos hecho feria. Luego nos explicaron que este terreno no tenía dueño, entonces los andinos nos dijeron «hay que posicionar acá». Eso era entre cinco familias, eran los fundadores. Ahí estaba mi esposo, mi tío, tía, todo entre familias. De ahí vino mi papá, mi mamá. Sí mi abuelita, yo tengo mi abuelita, ella tendrá ya 95 años. Y ella es la que nos enseñó todas las artes, los diseños».

Un mundo donde el trabajo se hereda y practica en la ciudad: «Somos dos hermanas, ella (Karina Pacaya) es la presidenta de esta comunidad. Lo que más me gusta es el arte, yo aprendí de mi abuela y de mi mamá, mi mamá aprendió de su mamá. A mí me gusta el arte, los diseńos de nuestras costumbres. Y pues, para no dejar nuestra costumbre. Yo a pesar de verme así, yo me pongo mi vestimenta, hablo en mi idioma nativo». Y, donde el sentido de identidad se define conscientemente: «Sí, sí me siento indígena. Mis hijos también hablan shipibo, hablan castellano. Porque soy shipiba, tienen que aprender mis hijos. Si mis hijos también son shipibos, no van a hablar solo en español. Si soy shipiba, mis hijos son shipibos también. Ahora que hemos venido a la capital, tienen que aprender los dos. Mi hija que está estudiando sabe shipibo, sabe castellano, sabe inglés. Mi hija también sabe hacer diseńos, me ayuda en trabajos que estoy haciendo en horas que están libres».

Una vida donde a diferencia de la familia criolla o mestiza los roles de responsabilidad frente a los hijos se comparten fundamentalmente en el mundo del trabajo: "Claro, porque mira en el hogar tenemos que hablar. De repente el hijo, la hija se van, esto está así, esto no. Ahí nos enseńa otra idea. No vamos a estar en la casa encerradas, eso qué nos va a enseńar. El marido 
se va a talleres o trabajos y se aprende más cosas, ¿y nosotras qué? Yo me siento con mi esposo y le digo: «sabes qué, tantos días hay talleres me voy», «ya vete, yo voy a estar dedicándome a los hijos».

Una situación donde el concepto de comunidad se resiste a renunciar a su tradición. Ante la pregunta si desea volver a su comunidad responde: «No. Nosotros no hemos pensado. Mejor es que nos den un espacio. Si nosotros vamos a un departamento, nosotros ya no vamos a ser una comunidad. Sería un espacio que nos den, y nosotros ver cómo hacer nuestras costumbres. ¿Nosotros acaso en la comunidad vivimos así en departamentos?, no vivimos. Y, nosotros ahora queremos que nos den un espacio, ya con el dirigente ver cómo arreglar, como salir. Que vengan los turistas, aquí hay bastantes turistas. Abajo (primer nivel) éramos así, nuestros stands eran bonitos y poníamos los collares. Pero, en un contexto donde: «Los andinos llenaban, llenaban, llenaban (se llenó el lugar de ellos). Ya pues, ahora estamos acá arriba, aquí ya no hay tantos andinos como se dice, aquí solo somos shipibos. Y ahora dicen que si arreglamos (el lugar) nos van a botar de acá. Por eso yo digo, hay que buscar un espacio, no vamos a vivir así. Mira, mi esposo tiene su pintura, y pinta acá. Yo también quiero mi espacio, mi cocina, el dormitorio de mis hijos, donde descansar. Acaso así va a ser en el departamento, no vamos a vivir así. Tiene que ser un espacio aquí. Hay algunos que tienen talleres de maderas, como el señor del costado, tiene taller de maderas de chonta, hace lanzas, flechas, toda clase de adornos en ese material. Tiene su máquina grande, es como un aserradero.

Surgiendo su vínculo estrecho con el mercado y la empresa: «Nosotros tenemos ideas para arreglar la comunidad. Hacer un centro, como una casita, para vender nuestras artesanías, hacer actividades. A veces nos dicen "por qué no se regresan a su comunidad", ¿pero nuestros hijos? Ya sé que allá hay enseñanza, pero no es la misma enseńanza. Nosotros nos regresamos y ¿dónde vamos a vender?, ¿acaso el turista va a llegar hasta la comunidad?, no va ir. De eso vivimos nosotros, y así vamos a mantener a nuestros hijos. Los hombres trabajan en varias cosas. Hay algunos hombres que están dedicados a la artesanía. Por ejemplo mi esposo, su trabajo es pintura. Se van a otros países, viajan a hacer sus exposiciones de pinturas. Mis hijos si me apoyan en la artesanía. Mi hijo mayor me ayuda bastante. Desde chiquito hacía artesanías. Mi hijo está en Senati, mi hija ya va a terminar su secundaria, tiene quince años.
Ellos quieren hacer una carrera, yo voy a poyarles hasta que se pueda. En vacaciones les llevo a mi comunidad, para que vean cómo sufrimos ahí. Mi comunidad es como una isla, ahí el agua le halaga, lluvia, ventarrón. Acá que mis hijos están creciendo, yo les llevo para que vean cómo he crecido allí. Y mis hijos me preguntan a veces «¿mamá así has crecido allá?».

Y, un mundo socioeducativo donde el "choque» cultural y lingüístico afecta a los hijos: «Ellos no han estudiado acá en la comunidad; pero eso sí, los dos mayores cuando eran chiquitos han estudiado en mi comunidad, allá en la selva. Yo traje a mi hijo mayor para tercer grado, y a la otra para primer grado. Cuando los traje y los puse a la escuela, para ellos, eso fue chocante. Porque no entendían el castellano. Todos los profesores que enseńan (en la selva) son mis paisanos, son shipibos. Y tienen que enseñar a hablar nuestro idioma. Escribir, leer en shipibo. Por un lado el castellano, pero no es igual. Por eso para mis hijos fue chocante. Me decían «mami cuando hablo mis amigos se ríen». Yo he ido a decirles a los profesores que yo soy así (shipiba), me dijeron «te vamos a ayudar», los niños comprenden. Desde su primaria, tiene amigos que vienen a visitarlo acá. Mis hijos están en el colegio del otro lado, el de Piedra Lisa. Sus hermanitos les llevan ahí.

Una vida que encuentra su curso directo en el sueño de hacer empresa. Dice: «Sí, con mi hermana estoy haciendo una empresa. Se llama "Meniin Ainbo", que significa mujer que hace cosas bonitas. En esta empresa hacemos artesanías, en tejidos, bordados, pinturas, pulseras. Hacemos por pedidos, nos dicen «necesito de este modelo tanto». En eso estamos trabajando con mi hermana. Todavía no tenemos un local, trabajamos en la casa de mi hermana (primer nivel), allí es el taller. Somos cuatro que estamos trabajando. Es una empresa familiar. Es un seguro para los hijos de cada una. Ayer me llamaron para hacer unas 300 pulseras tejidas en mostacilla. Cuando trabajo así es mejor. El año pasado estaba trabajando en limpieza en Maestro Home Center, en Minka, pero mejor me dedico a hacer mis cosas. Yo estaba trabajando y me llamaban que necesitaban tanto de este modelo. Así trabajando, en Minka, yo hacía mis cosas. Trabaja de la $1 \mathrm{pm}$ hasta las $10 \mathrm{pm}$. En la mañana me dedicaba a hacer mis cosas, y regresando así en la noche seguía cuando había pedidos. Además yo ya no estoy solo en Lima. El año pasado estuve en una feria internacional en Chile, allá estaba». 
El caso de Claudia Pacaya Cruz a diferencia de la mayor parte de los de su origen es un ejemplo saltante de movilidad social e incluso que el género no es un limitante pero son casos singulares. La pobreza estructural y el desarraigo marcan la dinámica de su grupo étnico social en el capitalismo global periférico.

\section{Caso 2. Crisis familiar y pobreza femenina urbana}

La familia en el Perú ha seguido en su estructura y funcionamiento una dinámica de la familia extensa, a la familia nuclear y hoy a la familia unipersonal o monoparental. En este curso histórico la situación de la mujer en las últimos cincuenta ańos se han dado profundos cambios en crecientes contextos de crisis de la familia extensa campesina o rural y/o nuclear más aún cuando llegan a la ciudad donde la diferencia cultural y étnica produce y reproduce profundas desigualdades y exclusiones.

El caso de Lucia Molina Mamani migrante de Huanchoy Cusco nos ilustra bien esta dinámica de reproducción a lo largo de su vida y mundo del trabajo. Vemos como en su experiencia se evidencia claramente la crisis de la familia rural en su proceso de desintegración y cambio. Cuenta que emigró a los 12 años. Era víctima de las agresiones físicas y verbales de su padrastro. Cuando era niña, se le cayó su hermanita de la espalda, la bebita no soportó el golpe y murió. Su padrastro de castigo agarró una cola de caballo que utilizó de correa y la comenzó a golpear; hasta hoy en día lleva una marca en el brazo producto de esa golpiza. A su padre lo vio muy pocas veces, y su madre no la defendía de las agresiones de su padrastro. En el Cusco ella comenzó a trabajar de empleada para una señora, luego esta seńora decide venir a Lima. Lucía se viene a Lima con la seńora, escapándose sin decirle nada a su mamá. Una situación difícil para ella, pues no tenía nada más que el trabajo que daba a la señora, no tenía familiar alguno en Lima, sumado a que solo hablaba su natal quechua.

Una trayectoria como ruptura radical con su lugar de origen pues recuerda que de los doce a los dieciséis ańos trabajó con la señora que la trajo a Lima, cuidándole sus bebes. Luego en los diversos trabajos que había tenido ha sido empleada del hogar cama adentro. Después cuando pasó a la convivencia con su pareja se dedicó a lavar ropa de casas y por años a chatarrear. El chatarreo es una actividad que lo dejó hace dos ańos. Chatarreaba de 8:00 pm a 3 o 4:00 am, pues en la noche es la hora que la gente vota la basura, luego en las mańanitas vendía la chatarra, normalmente sacaba de dinero de $S / .5$ a $S / .15$ soles, era una actividad que lo hacía a diario. Y en las tardes se iba a lavar ropa de alguna señora o limpiar casas cuando la llamaban.

Una vida donde el sentido de identificación legal del reconocimiento llega tarde dado que a la pobreza se une a la excusión en la ciudad. Señala que en Lima no tuvo documento alguno que la identifique hasta los 24 años. Un tiempo no tuvo donde dormir, y comenzó a dormir en la calle, en esos años existía el Toque de queda, al no tener documentos los soldados se la llevaron a la comisaría, allí estuvo por un mes. En la comisaría conoció un guardia que era del Cusco, este le pidió sus datos exactos, pues viajaría a Cusco y le iba hacer el favor de sacarle todos sus papeles. Después de unas semanas el señor el señor volvió a la comisaría trayéndole todos sus papeles a Lucía. Los padres de Lucía querían que ella regrese, le enviaron su pasaje para que vuelva, pero ella no quería y se quedó en Lima. Nunca viajó al Cusco, no sabe nada de su familia, no sabe si sus padres aún viven, no tiene comunicación alguna con ningún familiar.

Situación legal que en la ciudad se encuentra con el otro actor urbano estructuralmente también en crisis: su pareja. Señala que conoció a su esposo (conviviente nunca se casaron, pero ella lo llama así) hace 25 ańos. Cinco ańos estuvieron de enamorados, en ese entonces ella trabajaba en Jesús María de empleada del hogar para una monjas; luego Lucía sale embarazada pero no le dice nada a su esposo, en ese entonces enamorado, porque se da cuenta que era alcohólico y no trabajaba, vivía mantenido por sus padres en Ventanilla-Mi Perú. Lo dejo de ver, no le dijo nada de su embarazo. El proceso de su embarazo hasta el parto se dio en la casa de las monjas, estas monjas le dijeron a Lucía que les regale el niño, pues con ellas el bebé llamado Cristian iba a tener mejores oportunidades, ellas se encargarían de su educación, salud y comida. Lucía aceptó, trabajaba en la casa de las monjas a la vez que veía a su hijo, pero patria potestad le pertenecían a las monjas. Cristian llevó los dos apellidos de su mamá Molina Mamani. Al año de cumplido su hijo, Lucía se arrepintió, quería que las monjas se lo devuelvan, pero estas no quisieron. La sacaron del trabajo. Se volvió a encontrar con su enamorado, tuvieron otro hijo y se fueron a vivir a la casa de los papás de él, en VentanillaMi Perú. Sus suegros como tenían un terreno grande, la mitad solo la mitad de la casa lo había construido 
con madera, quedaba la otra mitad que era el patio, en una pequeña porción del patio hizo su cuarto de tripley y ahí vivió con su esposo y José María.

De ahí ha vivido en Ventanilla - Mi Perú -, ya casi 20 años. Para ella su esposo en vez de ser su hombro derecho, solo le causó trabajo. Ella madre y padre para José María, si bien es cierto su esposo nunca le fue infiel, pero tenía una enfermedad que era el alcoholismo y trabajaba muy eventualmente como carpintero solo cuando alguien le pedía que le haga algo. Lucía todos los días trabajaba y tenía que cuidar bien su dinero, porque si no su esposo ebrio venia y le cogía el dinero para vuelta irse a tomar. Cuando su esposo tomaba era por tres cuatro semanas seguidas, como no tenía dinero en vez de tomar cerveza solo tomaba «yonque o aguardiente» que es más barato y cuando no tenía dinero para comprar su aguardiente le robaba a Lucía su dinero, o se llevaba la ropa, ollas, sartenes o un animal (pollo, patos, gallinas) para venderlo y comprarse su aguardiente. Era una cosa de nunca acabar, por eso para Lucía salir adelante le era difícil porque tenía este obstáculo que era su esposo; ella no podía comprar nada para su casita porque había la posibilidad de que cuando ella regrese de trabajar ya no lo encontrara porque su esposo lo iba a vender. $\mathrm{Y}$ en ese ambiente su hijo José María crecía. José María absorbió todas las conductas negativas de su padre; un tiempo se dedicó a drogarse, se juntaba con los pandilleros, de vez en cuando robaba; Lucía ya no sabía qué hacer con los dos. Luego su esposo se enfermó de cirrosis, el médico le tenía estrictamente prohibido tomar. Cada vez que tomaba acababa en el hospital. Un día se fue a tomar cuando se venía de regreso a su casa se desplomó y hay mismo murió. Él mismo originó su muerte producto del alcohol. Este acontecimiento ocurrió el febrero del 2010.

Sobrevivencia que se estructura como un campo y hábitus personal y social a pesar del esfuerzo de aprender a leer y escribir. Cuenta que ella no recibió educación alguna, del Cusco vino a Lima analfabeta. Ya en Ventanilla en el colegio de su hijo, el Gobierno de Toledo se dio programas de educación para la lucha contra el analfabetismo. Allí ella aprendió a leer y a escribir, estuvo aproximadamente tres ańos, pero no tiene un certificado que haya estudiado porque no pasó con nota aprobatoria los exámenes. En la actualidad lo aprendido en ese programa le sirve, porque si puede leer, claro que no tan fluido y escribir también sabe, muchas veces con faltas ortográficas, pero lo hace. Sin embargo, con sus limitantes ella nunca dejó de trabajar, siendo el único sustento en su casa.

Bases que la llevan a ir tejiendo lazos sociales en su entorno y que en su contenido más profundo lo encuentra en la religión. Dice que al poco tiempo de morir su esposo, ya viviendo en el sector $\mathrm{M}$, unos mormones se acercaron a su puerta y la invitaron hacer parte de su iglesia. Le gustó la manera que le hablaron, y una de las razones más fuertes por la que entró fue por su hijo José María, quería un cambio en él. Y fue así, ella siente y ve que su hijo ha cambiado, ya no está metido en drogas, dejó de robar. En su gran avance en él. Otra de las razones fue por su esposo, para que su alma descanse en paz. Ella va todos los domingos de 7 am a 10 am a la iglesia de los mormones, se siente parte de ellos. La tratan bien, comparte sus discursos de lo vivido, lee la biblia. Se siente bien y tiene paz. Por lo que puedo ver, ella más que los bienes materiales, lo que más anhelaba es una familia. Pues de niña la trataron mal, y nunca tuvo ese calor de hogar; y cuando hizo su vida en Lima, le tocó un marido alcohólico por el cual no pudieron progresar juntos y constituirse como una familia. Por eso, al estar en esta nueva casa, saber que ya nadie le va a quitar lo que ella tenga y viviendo con su hijo y Paola, siente que por fin ha construido su familia, con necesidades tal vez, pero lo más importante es que están juntos y sin problemas de por medio. Por fin siente ese calor de hogar en ese terrenito del sector $\mathrm{M}$, que antes no lo podía encontrar.

Sus sueños de futuro es principalmente poder construir su casa, comprarse sus cosas y que su hijo le dé un nieto. También quisiera que su hijo tenga un trabajo fijo. Lo más bonito para ella en su casa construida viviendo con su familia que consta de su hijo, Paola y el nieto que a futuro se lo darán. Desea que algún día Cristian, que en estos momentos se encuentra en España, venga a visitarla porque hace más de cinco años que no lo ve. Ella se arrepiente de haberlo regalado, pero siente de qué hizo bien, porque ella no le habría podido dar lo que él tiene ahora. Pero ello no quita que lo extrańe, y se sienta triste de cuando en cuando.

\section{Caso 3. Bailando en el semáforo}

Las avenidas y calles en el mundo global se convierten en un gran teatro. Espacios públicos donde los actores viven toda su creatividad como humanos. Cada uno encierra una trayectoria social en un capitalismo global 
de sobrevivencias materiales y simbólicas. Cada espacio cultural concreto le da su singularidad entre la nueva riqueza y la nueva pobreza.

El niño o el joven danzante de música contemporánea son ejemplos típicos. Un medio de ingreso pero también de realización personal: «Lo hago porque me gusta el arte» dice el niño. Para Diego joven: «Para mí es un arte, porque hacer acrobacias es una actividad que no es fácil, toma su tiempo aprender a hacer esto, se gasta mucha energía física». La herencia estructural de la familia es la misma: «Mis abuelitos (maternos) pasaron gran parte de mi niñez conmigo, ellos me cuidaban y estaban todas las tardes conmigo, porque mis papas debían salir a trabajar, yo los quiero mucho. A mis padres los quiero a pesar que no los pude ver todos los días porque trabajaban todo el día, pero conforme fui creciendo me di cuenta de la realidad de mi casa y decidí salir a buscar algunas monedas para mi hogar. Mis tíos y mis primos nos visitan muy poco y ellos también tienen que trabajar muy duro para que puedan tener dinero en su casa».

El mundo del trabajo nace como una obligación para vivir en una experiencia que produce y reproduce su mundo social. Responde a las siguientes preguntas:

¿Trabajaste desde niño con tus padres? ¿Cuéntanos tu experiencia?

No, porque cuando yo me di cuenta que en mi casa faltaba comida tuve que decidir en salir a conseguir unas monedas más, para que mis hermanos puedan comer y mis abuelitos también. Al inicio salí a vender golosinas fue extraño con el tiempo me fui acostumbrando, hasta que con unos amigos nos decidimos a realizar acrobacias cuando los semáforos estén en rojo, se ganan bien si el día es bueno, en especial los fines de semana.

¿Si no te dedicaras a esta actividad en que te gustaría trabajar?

Yo creo que me seguiría dedicando a la venta de caramelos y alfajores al igual que mis padres. La actividad que hago me gusta mucho en realidad y trato de equilibrarlo con el colegio, pero a veces esto es más una necesidad que un gusto.

Una socialización donde la educación pasa como en los casos anteriores siempre a un segundo plano: "Mis padres me animan a seguir estudiando, ellos quieren que deje de salir a «semaforear» pero yo sé que si lo hago los gastos se acumularan y faltara el dinero, y eso es muy importante. Mis profesores a veces suelen llamarme la atención porque falto a clases por salir a trabajar, pero trato de explicarles mi situación y algunos me comprenden y me dan oportunidad y otros no porque son muy rectos.

Una socialización con los pares o los amigos bajo la influencia de los medios marcan la cotidianidad de la vida: "Mis amigos de por mi casa, la mayoría está solo en el colegio pero varios de ellos se dedican a vagar y no estudian, otros roban, yo prefiero hacer lo que hago ayudo a mi familia y me hace crecer como persona. Mis amigos como ya mencione se dedican a otras actividades, pero mis amigos con los que hago acrobacias ellos tienen historias similares a mi vida, aunque uno de ellos si se dedica a trabajar en otra cosa también, porque él es el sustento de su familia. La televisión no influyo en mí, a las justas tengo tiempo para verla porque en mi casa hay una y es bien chiquita, y el internet tengo que ir a cabinas y la mayoría de veces están llenas y prefiero estar en mi casa. Es divertido salir con la gente del barrio, pero como no paso mucho tiempo con mi familia prefiero estar un rato más con ellos y la escuela tiene su lugar solo que por cosas personales a veces tengo que faltar.

Experiencia donde la calle se invisibilidad porque prima la responsabilidad de vivir. ¿Qué significa para ti vivir en la calle? «No vivo en la calle, pero paso tiempo en ella y es especial porque lo considero como mi segundo hogar». ¿Qué experiencias positivas y negativas tiene vivir hoy en la calle? "Las positivas son el tiempo que comparto con mis amigos con los cuales semaforeo, son como una segunda familia para mí porque pasamos varias horas juntos y las negativas son las malas mańas que se enseñan en la calle como robar o todo eso que malo que ves» ¿Cuáles son los temas de conversación más frecuentes? "Más que todo que queremos hacer cuando terminemos el colegio, varios de nosotros tenemos sueños que queremos realizar y también hablamos de la familia y de la escuela. La calle ha cambiado mi vida porque tengo más responsabilidades y eso hace que quiera salir adelante, tengo muchas motivaciones. Recuerdo que un día un señor me dio 10 soles de propina, fue un muy buen día. Otra fue cuando los serenos nos comenzaron a perseguir. Veo que en el Perú habrán más oportunidades y me gustaría que adolescentes como yo no tengan que trabajar y que el Estado los pueda apoyar. La familia tiene que seguir siendo unida, la familia es lo más importante pero no todos lo valoran y en un futuro con todo lo que vemos se pueden dar más casos de familias que no están juntan. Tengo muchas ganas de salir adelante y querer cumplir sus sueńos, para que puedan ser felices 
y dar felicidad a sus seres queridos. Mi sueño es ser arquitecto, sé que es una carrera cara, pero sońar no cuesta nada y eso nadie me lo quitara».

Un sentido de la vida donde te encuentras contigo mismo y los otros. ¿Qué significa para ti ser feliz? «Significa estar en paz con las personas que amas».

\section{Caso 4. El vendedor de sueños}

Juan Carlos es un niño de 10 años que inmigro con su hermano mayor hace 3 años desde su natal Huaraz, específicamente de Sihuas lugar donde vivía con su madre y sus hermanos. Actualmente vive en el distrito de San Juan de Lurigancho en el sector de Canto Grande. Me comenta que extraña a su madre y hermano menor, ya que allá vivía con ellos. En el plano familiar sobre su historia de vida de sus abuelos indica que no conoció a su padre, por tal motivo me habla de sus abuelos de parte materna, su abuelo Máximo nació también en Huaraz, el es un hábil carpintero, le enseño todo este labor e incluso le enseño a tallar sobre madera la figuro o nombre que él quisiera, barnizándolo para una mejor presentación, es así que para Juan su mayor influencia artística y creativa será su abuelo. El inmigro junto a su hermano para buscar una mejor forma de vida y para enviar dinero a su madre.

El segundo día lo encontramos sentado en un pequeño banco, con un cincel, maderas pequeñas y barniz haciendo uso de su habilidad y creatividad. Dentro de las personas escuchaba decir, "Este niño es un artista con las manos», tallaba un corazón con sus nombres para una pareja de enamorados que esperaba muy ansioso su recuerdo de amor. Su hermano mayor estaba en una esquina, elaborando otros llaveros a los eventuales transeúntes, comenta que su hermano lo cuida desde ahí.

Su experiencia laboral comenzó en Lima junto a su hermano, trabajan desde las 3 a 7 de la noche de lunes a viernes y los sábados y domingo a partir de las 11 de la mañana hasta las $7 \mathrm{pm}$. Cada llavero lo vende al precio de un sol y gana diariamente entre 15 y 20 soles, su hermano hace recuadros fotográficos, me comenta que el próximamente también quiere aprender a hacerlos. A pesar de ser un niño tiene una gran madurez para enfrentar los problemas al preguntarle si la actividad que desarrolla es un trabajo y/o arte contesta: «el arte es crear, y en mi trabajo utilizo la imaginación",

Asiste a una escuela estatal pero hay veces que suele faltar porque se queda dormido, le gusta el colegio y estudiar, quisiera ir todos los días me comenta, pero amanezco muy cansado, a veces le duele las manos y el tallado le produce ciertas ampollas, se considera un alumno regular, dentro del colegio no tiene mucho amigos ya que por su condición de ausente a muchas clases no ha podido sociabilizar con todos, le gustaría tener más amigos, pero primero es el trabajo, «como dice mi hermano».

La calle marca la cotidiandad de su vida. Al principio le causaba mucho miedo, temía ver pasar a tanta gente, los carros, el ruido, pero confiesa que poco a poco se va adaptando. En la calle ha hecho amigos y amigas que como el experimentan la experiencia de trabajar a tan temprana edad en los pocos momentos que no tiene clientes esperando ser atendidos, juega con los niños que también trabajan a su alrededor, aunque le gustaría tener mucho más tiempo de esparcimiento sabe y es consciente de que primero tiene que trabajar, después estudiar y si sobra algo de tiempo quizás jugar.

La escuela le ofrece un mundo que no responde a la inmediatez de sus necesidades básicas. Una institución lejana e incierta. Ante esta situación los sueños de futuro son muchos, el aún cree en la posibilidad de un país más consciente de sus carencias, antepone ante todo a su familia que se encuentra lejos. El arte como herramienta de trabajo es al fin y al cabo la manera en cómo este niño ha conocido las necesidades y empieza a enfrentar el camino llamado vida.

\section{Caso 5. Los danzantes de break dance}

Otro caso saltante es el de Juan Martín tiene 17 años quien nace en la Victoria El Porvenir y actualmente reside en un pequeño lugar alejado del distrito de Los Olivos "Puente Camote». Su familia es de tipo monoparental. $S$ sus padres se separaron cuando él era apenas un infante, actualmente el vive con su abuela materna. Su madre biológica lo abandono situación que lo llevó al cuidado de su abuela:«Mi abuela lo es todo para mí, yo no tuve padres, y tocar de ese tema me hace sentir muy mal, bueno, a mi abuelita le digo madre, siempre lo hice, ella me ayudo en muchas cosas, como te comentaba, anteriormente me había ido de mi casa porque no tenía el apoyo suficiente, me sentía solo y me deje llevar por mis amigos del barrio y esas cosas que te desconciertan. Actualmente ya vivo con mi abuela y la trato de mantener y apoyarla en todo lo posible, regresé a casa a los 16 años, volví a vivir con mi abuela. Y sé que a pesar de mi desobediencia y mi 
berrinchez dejé, por un año, de lado a mi madre, me arrepiento de algunas cosas, pero no del todo, porque saliendo del hogar aprendí mucho en las calles, si no hacia lo que hice nunca estaría donde estoy. Mi abuela es mi motor y motivo ahora, la quiero mucho, y lo mejor es que me apoya en todo ahora.»

Tuvo estudios en un colegio nacional, en el que no aprendió mucho. Su abuela no podía mantenerlo en un colegio de mayor calidad, el problema siempre fue los recursos económicos y la solvencia familiar del día a día. Su abuela se ganaba el pan de cada día vendiendo papas rellenas a las afueras de su colegio. A los 15 años, Juan Martín decidió irse de su hogar, por rebeldía y las juntas con las cuales andaba y porque no tenía el apoyo suficiente en las cosas que el realmente quería hacer. Una de ellas era dedicarse al arte del baile y trabajar de esa manera. Es por ello que se fue a vivir a la casa de un amigo de su barrio, que lo conoce desde la infancia que se dedicaba a lo mismo, compartían sus sueños e ideales. El irse del hogar fue una causa de cómo al sociedad se imponía hacia él, en sus acciones y reacciones. Desde su temprana edad, ya sentía que era trabajar y mantenerse por sí mismo, obviamente dando dinero al hogar de su compañero al cual había sido acogido sintiéndose cada vez más independiente.

El se dedicó a realizar piruetas y saltos mortales en las calles, en los semáforos de las avenidas Carlos Izaguirre, justo al frente de la municipalidad distrital, fascinando así a los transeúntes y choferes los cuales se quedaban admirados al verlo. Primeramente empezó de esa manera, a ganarse un sencillo de la gente y así poder darse un almuerzo, o una cena. Luego, el nos comenta que a la edad de 17 ańos, caminando con su amigo Leo (18), encontraron un festival de música hip hop y rap en vivo, realizado en el Campo de Marte, la cual les llamo la atención. Desde allí se enfocaron al arte del Break dance, empezaron a practicar en las calles, y a estilizar sus pasos, ganando de esta manera mucho más atención del público, realizando algo innovador. Testimonia que «el break fue algo que desde un inicio, me llamo mucho la atención, con full practicas y ensayos nos fuimos ganando a la gente, nos dábamos cuenta que íbamos recolectando más dinero que antes... así que al break dance le debo todo, todo lo que ahora soy».

$\mathrm{Su}$ actividad es entendida como trabajo y arte pues piensa que «son ambas cosas, trabajo porque me dedico a eso y trato de llevarme algo a casa, y un arte porque aprendí en las calles a realizar piruetas y saltos mortales, me costó mucho desde niño aprender, pero era lo que siempre me gustaba hacer. Y de ahí realizar break dance nos llevo a tener más ingresos, a la gente le gusta mucho ver esas cosas, les llama la atención el pararnos de cabeza hacer bailes de la calle y esas cosas. Y ahora que pertenecemos a D1 nos dio más oportunidades de crecer y poder sacar adelante a mi hogar, a mi abuela. No veo otro trabajo para hacer, me desempeńo muy bien en esto, si hablar y ser muy amigable con los demás, entablar conversaciones rápidamente, si ese fuera un trabajo creo que mejor me dedicaría también a eso.) Soy muy conversador, siempre lo fui».

La calle es la vida siempre informándose a través de Internet: «nosotros vamos a veces al internet a parte de conversar con nuestras amistades actuales, nos ponemos a ver videos de break dance, esas competencias que realizan en otros países y aprendemos de ahí... y a veces que nos ponemos a jugar algo». Un mundo de vida donde «Vivir y compartir lo que hago con mi amigo (Leo), es nuestra vida, hacemos lo que nos gusta, simplemente es nuestra felicidad, crecimos y ya van muchos años que nos conocemos empezando aquí, en los semáforos. A él lo conocí en mi barrio, en la calle, nuestro punto en común era hacer las piruetas y saltos jugando cada fin de semana, realizamos esto desde que teníamos 10 años más o menos, siempre nos gustó lo extremo, nuestro lema es «a desafiar a la gravedad» y todo eso... es lo que nos gusta para nosotros, simple y sencillamente eso".

Cotidianidad que marca los temas de conversación: «Siempre hablamos sobre lo que hacemos, la música y los estilos de hip hop es de lo que hablamos, siempre que bailamos ponemos una pequeña buffer que tenemos, que reproduce la música desde nuestro USB y nos pasamos el tiempo escuchando y practicando ese tipo de cultura musical. Es lo que más hablamos. Desde el ańo pasado pertenezco a ángeles de D1, fue algo muy bonito, me emocione mucho al ir al casting ese día con Leo y ver cuántos jóvenes como nosotros realizaban lo mismo... Nosotros pensamos que nunca íbamos a pasar, hasta que mencionaron nuestros nombres y nos dijeron que pasamos. Que si tenemos el talento suficiente, nos dieron una beca completa para cada uno, ahora solo vamos a practicar 3 veces por semana, porque también nos ponemos a trabajar aquí en los semáforos como vez, pero necesitamos dinero para nuestros pasajes e ir hasta magdalena a practicar se nos hace un poco difícil pero ahí nos las conseguimos». 
Una vivencia que construye la felicidad desde su entorno buscando imitar a las estrellas de la televisión: «Estar aquí, compartiendo con mi mejor amigo todo y sacarle alguna sonrisa y algunas moneditas a la gente que nos mira... (risas) el ser feliz es realizar lo que más te gusta y apasiona, y mucho mejor si con eso te ganas la vida, como decía mi abuela, ser feliz es brillar, es mirar una estrella y decir «una persona con talento brilla por si sola, nunca dejará de brillar ante los demás, si sale ante el gran cielo e ilumina, también nosotros, si te demuestras, iluminas, así es como uno sale adelante y demuestra su talento ante los demás, es como las estrellas de la televisión».

Y, donde los sueños de futuro se construyen desde el entorno inmediato de identificación: «Mi mayor sueño es apoyar a mi familia, es lo fundamental, a mi abuela que es la única persona a la que tengo, quien me respalda en todo, y pues también crecer como artista, en lo que hago, tampoco quiero ganarme la fama, eso no va mucho conmigo, lo que quiero es que todos tengan el mismo apoyo como lo tengo yo y Leo, la oportunidad de poder crecer con lo que realizamos, derrepente fuimos afortunados en tener ese privilegio de estar en D1 pero creo que hay muchos que están en las calles realizando lo mismo pero no tienen la oportunidad como nosotros de poder ir y crecer en este arte. Trabajar así, semaforeando, que toda la gente te mire, se ríe, les gustes, o sientas su indiferencia, para muchos, dirían que es difícil... pero cuando algo te apasiona y quieres seguir adelante, no hay marcha atrás, no existe la palabra difícil. Si habría más apoyo a la gente que tiene arte y talento en las calles, apoyo del Estado en sí sería muy bueno, en la tele nomas puedes ver tanto talento que tiene la gente, pero anda mira cómo viven... son como nosotros, no tienen una casa propia, no comen si no trabajan y cosas así».

Otro caso es el de Andrés Gustavo "Del Tavo» de 20 ańos nace y vive en Comas, de padres provincianos, su padre de Cerro de Pasco y su madre de Huánuco. Hoy separados. Nos dice: «Solo vivo con mi padre, como te dije mis padres son separados. Mi abuelo desde chiquito me crió pe, mi abuelo ya falleció he vivido con mis abuelos en Cerro de Pasco. Ahí mis abuelos me enseñaron a trabajar y levantarme temprano».

Una socialización con el padre desde su propia individualidad: «Bueno mi familia, ahí ta tranquilo, nos apoyamos de otra forma, me ha dado cierto consejos han influido poco. Bien mi padre si me apoya bastante Yo, normal o sea yo trabajo y normal en mi casa, ya es elección de cada uno. O sea yo con el dinero que gano me compro mis cosas, ahora ya me comprado mi televisión y ropero y todo. Junto mi plata e invierto en comprar mis cosas, de ahí voy a comprar mi equipo. Quiero comprarme un Play Station pero también gasto en mi pasaje».

Proceso que se afirma en el mundo del trabajo: «Yo comencé trabajar desde los trece años, con mi mamá. Yo trabajé vendiendo cigarro y otros trabajos con $\mathrm{mi}$ mamá de ahí comencé a practicar el arte de la calle el Break Dance y así. O sea veía video en youtube y veía que practicaban este arte salían a otros países EE.UU, Colombia, Brasil, parte de Ecuador. En Ecuador hay más cultura que Perú, en Europas es más fuerte este arte. Ya pe todos tenemos diferentes estilos algunos bailan. Practico en el piso la pista y ahí es donde me he hecho lesiones como me estás viendo me he roto mi labio y fracturado mi pierna».

Actividad que se afirma entre el juego y el esfuerzo de obtener un ingreso para vivir: «Para mí es un trabajo porque me mantengo de esto, vivo de este trabajo también podría decir que es un arte, porque entreno mucho paras hacer piruetas. Tal vez sí, a veces la calle es dura a veces no hay te tratan mal las personas y los serenazgos o me confunden con ratero pero hay gente que si valoran mi trabajo porque saben que es arte. Obtengo un promedio de 15, 20. Trabajo de $11 \mathrm{am}$ hasta 10 un aproximado yo la guerreo hace, a veces me quedó hasta más tarde. Yo trabajo solo, yo me siento solo. No me conviene trabajar en grupo, la ganancia sale dividido o sea cuando yo trabajo me preocupo por mí mismo, no me conviene trabajar en grupo».

Trabajo que se hace cotidiano a lo largo de toda la semana: «Trabajo los lunes, martes y miércoles, pero es esfuerzo ya sale algo, los buenos días son el sábado y domingo. Si estoy por la Molina gano más y otros podios pero en general me va bien. Trabajo todos los días a veces descanso los lunes por ser días bajos. A veces me quedo practicando nuevos pasos, la mayoría de los jóvenes practican duro hay veces hay competencias y batallas el que gana es la figura y lo tienen más respeto».

Una situación socioeducativa marcada cada vez más por la competencia y el mercado: «Mis padres más se dedicaban a su trabajo me impulsaban para ir al colegio me ayudaban en lo que podía. Bueno mis profesores si han sido bueno conmigo me apoyaban hasta el último pero no era suficiente, me faltaba una persona que me guie, que me oriente, desde niño yo 
he sufrido bastante. He sido un alumno medio regular, a veces me escapaba del colegio para irme con mis amigos. Me dedicaba más a jugar al internet, no le tomaba mucho interés al estudio».

Mundo social que se entreteje con el grupo de pares en el barrio donde se reproducen las mismas trayectorias: «Mis amigos eran más de barrio también practicaban en Break Dance ellos me enseñaron para junto con ellos, son personas en quien confío amigas tengo muchos pero más me dedico a trabajar»

Bajo la creciente influencia de los medios de comunicación masiva en una individuación de los gustos: «Nada, solo veo programas como Cartoon Network, veo un rato de ahí veo películas es para distraerme. Si veo que sale zapatillas Nike y quiero tener uno o los artefactos que salen. Más voy al internet a jugar a entrar a mi Facebook. Juego Gund Baud, Star Craft, motos me gusta bastante ya estoy juntando mi plata para comprarme mi computadora. Más paro jugando con mis amigos teníamos un grupo comenzamos a practicar y hacer batallas del Break Dance de ahí salía un representante para ir a concursar a otro lado mi barrio si me influyó bastante en mi arte».

Y, donde la calle marca la vida cotidiana: «Aprendo valorar más mi trabajo ya yo mismo me compro mis cosas o sea vestiste bueno ya comenzaré a estudiar ya, también aprendo a valorar el dinero que gano o la guerreo para sobrevivir no es fácil trabajar en la calle a veces estoy cansado o triste pero igual tengo que trabajar, he hecho buenos amigos en la calle. Es peligroso vivir en la calle, pero se cuidarme solo a veces me molestan pero ya estoy acostumbrado. No me gusta trabajar en la calle aunque también estaba pensando en estudiar. Con mi amigo Anthony converso sobre el Break Dance para ir a concursar siempre me aconseja para ir a practicar. Soñamos con viajar a otros países, Brasil, Colombia, para competir. A los demás no les importa practicar ahí lo dejan».

Por otras parte dice: «La calle me ha hecho madurar más yo mismo me organizo en mi trabajo, también he aprendido valorar más mi trabajo, siempre quiero salir adelante no quiero quedarme atrás. La verdad uno mismo tiene que hacerse solo, el estado no ayuda mucho, yo siempre voy a seguir luchando con mi trabajo. Por ejemplo el que practica el Break Dance y los que son buenos los llaman para concursar y ahí le dan su propina, dinero de ahí ya lo toman como un trabajo algunos tienen que poner una academia de enseñar eso el futuro de algunos jóvenes que practican este arte. Me gustaría ir a Colombia y concursar pero yo no tengo mucho apoyo. Me gustaría sr un gran artista de Break Dance o pone i pastelería también viajar por todo el mundo enseñar este arte o taller poner mi academia si es que tengo apoyo de alguien pero también estar al lado de mi familia».

¿Qué significa para ti ser feliz? «Estar aquí o estar con mis padres tener apoyo de ellos y poder compartir cosas. Acá en la calle se sufre mucho. Si vivir juntos en familia y trabajar y todo eso».

A modo de conclusión podemos destacar que los nuevos pobres en Lima procesan nuevas dinámicas de cambios socios económicos, sociales, culturales y de identidades expresados a su vez en nuevos en procesos, formas y contenidos de desigualdad y exclusiones. Los actores étnicos indígenas redefinen su situación en este contexto urbano más en la exclusión que la inclusión. El sueño femenino de un nuevo mundo del trabajo y familia se anhela ante la exclusión global. El trabajo precario busca la sobrevivencia en la urbe en una creciente competencia por vivir antes que educarse producto de la privatización global. Todo en un mundo de imaginarios donde los sueńos y vida de nińos y jóvenes buscan en la heterogeneidad y homogeneidad vivir la vida bajo el creciente impacto de la industria cultural hegemónica del consumo.

\section{Referencias bibliográficas}

Antunes, Ricardo. (2014). La nueva morfología del trabajo y sus principales tendencias: Informalidad, infoproletariado, (in)materialidad y valor. En Estrada, Jairo (Coordinador). América Latina en medio de la crisis mundial Trayectorias nacionales y tendencias regionales. Buenos Aires: CLACSO.

Banco Interamericano de Desarrollo, y Programa de las Naciones Unidas para el Desarrollo. (1993). Reforma social y pobreza. Hacia una agenda integrada de desarrollo. Washington $D C$.

Banco Mundial (1993). Implementing the World Bank's Strategy to Reduce Poverty. Progress and Challenges.

Barba, C. (2009) Los estudios sobre la pobreza en América Latina. http://www.ejournal.unam.mx/rms/2009-5/ RMS009000502.pdf

Bauman, Z. (1999). Trabajo, consumismo y nuevos pobres. Barcelona: Gedisa Editorial. 
Bialakowsky, Alberto y Costa, María. (2017), Versiones y reversiones sobre las poblaciones trabajadoras extinguibles, Revista de Ciencias Sociales, Buenos Aires: UBA.

Bourdieu, P., y Wacquant, L. (1995). Respuestas. Por una antropología reflexiva. México: Grijalbo.

Buitrago, R. (2010), «La falacia del desarrollo basado en apertura comercial». En Andrade Pablo y Puyana, Alicia, La pobreza en América Latina, Buenos Aires: CLACSO.

Carreteiro, T. (1993). Exclusion Sociale et Construction de l'Identite. L'Harmattan. Paris: Santé, Sociétés et Cultures.

Castoriadis, C. (1986). "Lo imaginario': la creación en el dominio histórico-social». En Los dominios del hombre. Las encrucijadas del laberinto. Barcelona: Gedisa.

Cattani, A., Mota, L. y Cohen, N. (2013), A construcao Justicia Social na América Latina. Porto Alegre: Tomo Editorial.

Cepal (2015). Panorama social de América Latina. ONU

Cimadamore, Alberto. (Comp.) (2008). La economía politica de la pobreza. Buenos Aires CLACSO.

Contreras, C. comp. (1999). América Latina en el siglo XXI. De la esperanza a la equidad. México: Fondo de Cultura Económica y Universidad de Guadalajara.

Cornil. P. (1995). Nouvelles Formes de Pauvreté. Analyse phenomenologique d'un groupe a risque: Les Jeunes Femmes peu qualifiées. Travail de fin de'études présenté en vue de l'obtention du grade de Maître en Sociologie. Septembre U.C.L.

De Ferranti, D.;. Perry, G. ; Gill, I.; y Servén, L. (2000). Asegurando el futuro en una economía globalizada, Washington DC: Banco Mundial.

De Sousa Santos, B. (2011). Una epistemología del Sur: La reinvención del conocimiento y la emancipación. Buenos Aires, CLACSO - Siglo XXI Editores.

Dubet, F. (1987).La Galère : jeunes en survie. Paris: Fayard.

Eguía, Amalia, Ortale, María y Piovani, Juan (Compiladores) (2015). Género, trabajo y politicas sociales. Buenos Aires: CLACSO.

FAnOn, F. (1969). Los condenados de la tierra. México: FCE.

Foucault, M. (1987). "El orden del discurso». Cuadernos Marginales núm. 36. Barcelona: Tusquets Editores, 1987.

García Canclini, N. (1995). Consumidores y ciudadanos: conflictos multiculturales de la globalización. México: Editorial Grijalbo.

Giddens, A. (1993). Consecuencias de la modernidad. Madrid: Alianza Universidad.

Harvey, D. (2005). El «nuevo» imperialismo: acumulación por desposesión. Buenos Aires, CLACSO
Hoggart, R. (1970). La culture du pauvre. Étude sur le style de vie des classes populaires en Anglaterre. Les Editions de Minuit. Paris.

Kerner, D. (2000). «The Washington Consensus: A Theoretical Reappraisal». Ponencia presentada en el Congreso Internacional de la Latin American Studies Association, 2000.

Labbens, J. (1978). Sociologie de la Pauvreté. Le TiersMonde et le Quart-Monde. Paris: Collection Idées. Gallimard.

Lewis, O. (1969). La Vida: Une Famille porto-ricaine dans une culture de pauvreté: San Juan et New York: Editions Gallimard.

Martins, P. (2012). La decolonialidad de América Latina y la heterotopía de una comunidad de destino solidaria. Argentina: CICCUS-Estudios Sociológicos Editora.

Offe, C. (1991). Contradicciones del Estado del bienestar. México: Conaculta y Alianza Editorial.

Ogien, R. (1983). Théories ordinaires de la pauvreté. Paris: PUF.

Quijano, A. (1969).Redefinición de la dependencia y proceso de marginalización en América Latina. Santiago de Chile: OIT-ILPES.

Quijano, A. (2000). «Colonialidad del poder, eurocentrismo y América Latina», en E. Lander (comp.), La colonialidad del saber: eurocentrismo y ciencias sociales. Perspectivas Latinoamericanas. Buenos Aires, CLACSO.

Quijano, A. (2014). "Bien vivir: entre el desarrollo" y la des/colonialidad del poder», en Des/colonialidad y Bien Vivir. Un nuevo debate en América Latina. Lima, Cátedra América Latina y la Colonialidad del Poder - Universidad Ricardo Palma

Parker, C. (1992) Animitas, Machis y Santigüadoras en Chile. Ediciones Rehue. Santiago de Chile

Pimentel, C. (2013). Vidas Marginales, Santiago de Chile: ediciones metales pesados.

Ríos, J. (2011). El quehacer sociológico en América Latina Un diálogo teórico con sus actores. Lima: UNMSM.

Salama, P. (1999). Riqueza y pobreza en América Latina. La fragilidad de las nuevas políticas económicas. México: Fondo de Cultura Económica y Universidad de Guadalajara.

Sandoval, M. (2014). Sociología de la pobreza urbana https://www.google.com.pe/\#q=+Dubet+y+la+pobreza

Singer, P. (1997). "Economia solidária: geração de renda e alternativa ao liberalismo». Proposta. Río de Janeiro: FASE.

Singer, P. (2002). Introdução à economia solidária. São Paulo: Fundação Perseu Abramo. 
Sojo, C. y Gacitúa, E. Coords. (2000). Exclusión social y reducción de la pobreza en América Latina y el Caribe. San José de Costa Rica: Flacso y Banco Mundial.

Thorp, R. (1998). Progreso, pobreza y exclusión. Una historia económica de América Latina en el siglo XX. Washington DC: BID, Unión Europea.

Thorp, R. Paredes, M. (2011). La etnicidad y la persistencia de la desigualdad. El caso peruano. Lima: IEP.
VARIOS (2012). Las Relaciones Internacionales de la Pobreza en América Latina y el Caribe, Buenos Aires: CLACSO-CROP.

Vercauteren, Paul. (1970). Les Sous-Proletarires. Essai sur une forme de pauperisme contemporain. Licence en Sciences Politiques et Sociales. Les Editions Vie Ouvriere, Bruxelles. 